\title{
Novel colloidal poly(MA-alt-1-dodecene)-g-PEO/ODA- MMT/AgNPs nanohybrid composites as antimicrobial, antifungal and anticancer platforms
}

\author{
D. Demircan ${ }^{1}$, Z. M. O. Rzayev ${ }^{2 *}$, K. Salimi ${ }^{3}$ \\ ${ }^{1}$ Department of Chemistry, Hacettepe University, Beytepe, 06800 Ankara, Turkey \\ ${ }^{2}$ Institute of Science \& Engineering, Division of Nanotechnology and Nanomedicine, Hacettepe University, Beytepe, \\ 06800 Ankara, Turkey \\ ${ }^{3}$ Department of Chemical Engineering, Faculty of Engineering and Natural Sciences, Ankara Yildirim Beyazit University, \\ 06010 Ankara, Turkey
}

Received 22 December 2017; accepted in revised form 29 March 2018

\begin{abstract}
This work presents a new approach to synthesize the colloidal ODA-MMT-poly(maleic anhydride-alt-1-dodecene)$g$ - $\alpha, \omega$-methoxyhydroxyl-PEO/silver nanoparticles (AgNPs) nanohybrid composites (NHC) using the following synthetic pathways: (1) complex-radical alternating copolymerization of maleic anhydride with 1-dodecene $\alpha$-olefin comonomer, (2) grafting of PEO onto alternating copolymer through esterification, (3) intercalating a copolymer- $g$-PEO between organoclay layers via complex formation of maleate carboxyl with octadecyl amine, and (4) in situ generation of AgNPs in polymer nanocomposite by annealing method under vacuum. The obtained multifunctional NHCs with different contents of AgNPs were characterized by UV spectroscopy, $\zeta$-potential and size analysis methods. It was demonstrated that annealing of the colloidal NHC is accompanied with in situ generation of stable and partially protonated AgNPs due to specific reducing and stabilizing effects of multifunctional matrix polymer contained positively charged reactive and bioactive sites. Antibacterial and antifungal activities against Gram-negative and Gram-positive bacteria and fungal microorganism were investigated. The cytotoxic, apoptotic and necrotic effects in NHC/L929 fibroblast cells systems were evaluated. The synthesized watersoluble, biocompatible, and bioactive colloidal NHCs are promising candidate for a wide-range of applications in air filtration, food packaging systems, bioengineering, especially in tissue regeneration and nanomedicine.
\end{abstract}

Keywords: biocompatible polymers, alternating copolymer, copolymer-g-PEO, AgNPs, colloidal NHC

\section{Introduction}

It is crucial to prevent microbial and viral infections as a results of microbial contamination, epidemiological factors, and infection risks in many areas, especially in clinics, hospital, food packaging sector, and dental equipments. Therefore, attention of many researchers was focused on the fabrication and application of a new generation of functional polymer nanostructures, and polymer-biopolymer/inorganic nanofiller hybrid composites with desired properties such as antimicrobial and superhydrophobicity [1-6].
Among them, silver nanomaterials include silver nanoparticles, stabilized silver salts, silver-dendrimers, silver-polymer and metal oxide composites, and activated carbon materials demonstrated antibacterial effect against high toxic organisms [7]. In addition, silver-enhanced zeolite, antibacterial polymer thin films containing silver cations-zeolite additives can be also included into this classification [8]. The effect of synthetic and biopolymer based surfactants on the stability and bioactivity of silver nanparticles were investigated. Additionally, the antibacterial activity 
of silver ions $[9,10]$ and $\mathrm{Ag}^{+}$-carrying polymer materials were reported in the literature [11-14]. However, the antimicrobial properties of Ag-nanoparticles which formed through in situ processing during the synthesis and thermal treatment of polymer layered silicate nanocomposites, nanocoatings and nanofibers has not been investigated.

The use of silver as a metal can be traced back to times even before Neolithic revolution. Moyer first recorded the medicinal use of silver during $8^{\text {th }}$ century [15]. Now, silver nanoparticles have promising applications in biotechnology and life sciences due to their remarkable optical, electrical and antimicrobial properties. Recently, various synthetic methods have been developed for the fabrication of Ag-nanoparticles, which includes thermal decomposition [16], sonochemical synthesis [17], chemical reduction [18] and laser ablation [19]. Recently, the fabrication and application of a new generation of functional polymers, nanomacromolecular systems, and polymer-biopolymer/inorganic nanofiller hybrid composites were reported. In order to fabricate nanostructures in biopolymer/silver nanoparticle systems, peptides, proteins which are produced by bacteria and fungi, components of nucleic acids, hollow biological compartments like virus particles, plants, and etc. have been utilized [20-23]. Most of the techniques that are used to incorporate silver into polymeric matrixes involve either chemical modifications such as reduction $[18,24]$ or synthesis of complex silver compounds [25], mixing preformed silver particles with polymers [26]. Most silver-containing antimicrobial polymers contain either elemental silver, which has a very low rate of dissolution in aqueous environment, or highly water-soluble silver salts or silver (I) complexes [27, 28]. Taking into consideration the known different approaches and application of various types of polymer and biopolymer systems in the synthesis of silver nanoparticles, these new synthetic pathways can be divided to the following groups: syntheses by using (1) the synthetic polymer surfactants-stabilizers, (2) the biopolymer, especially carboxylated polysaccharides with surfactant properties, (3) various microorganisms, (4) the DNA macromolecules with linear helical structure and (5) the plasmid DNA as templates.

In last years, attention of many researchers was also focused on synthetic and biopolymer based surfactants which significantly influenced on the stability and bioactivity of silver nanoparticles. Allain and
Vo-Dinh utilized the silver/PVA surfaces as a silvercoated microarray platform to detect labeled DNA relating to breast cancer gene using the dye rhodamine B [29]. Muraca et al. [30] reported the effect of Ag-nanoparticles (AgNPs) seeds on the growth and magnetic properties of $\mathrm{Ag}-\mathrm{Fe}_{3} \mathrm{O}_{4}$ heterodimer NPs prepared using two steps chemical approach. They observed that at low concentration, the 'flower' type of NPs is more favorable whereas the higher concentration of Ag-NPs seeds promotes the growth of dimer type structures. A green synthesis of silver NPs using extracts from the aerial part of Artemisia capillaries was reported by Park et al. [31]. They showed that both water and $70 \%$ ethanol extracts successfully generated silver NPs with an average diameter of 29.71 and $29.62 \mathrm{~nm}$, respectively. They also observed an improvement in antibacterial activity (MIC $8.35-16.7 \mu \mathrm{g} / \mathrm{mL}$ ) against a total of twenty different strains of G-negative and G-positive bacteria. They showed that, plant extracts have a potential to be utilized as powerful reducing agents for the production of biocompatible silver nanoparticles possessing enhanced antibacterial activities. Nomiya and coworkers $[32,33]$ reported the synthesis, characterization, antifungal and antibacterial activities of silver complexes with various organic ligands. Silver nanoparticles (NPs) were prepared using silver nitrate $\left(\mathrm{AgNO}_{3}\right)$ as a precursor in an aqueous solution of poly(ethylene glycol) (PEG, $M_{\mathrm{n}} 100000 \mathrm{~g} / \mathrm{mol}$ ), which acted as both a reducing and stabilizing agent [34]. Generally, AgNPs compared with $\mathrm{TiO}_{2}, \mathrm{Cu}$ and $\mathrm{ZnO}$ nanoparticles exhibited higher antibacterial activity and low cytotoxicity to human cells, and applicable for biomedical and clinical fields [35, 36]. Mechanism of antibacterial actions of AgNPs were explained in the literature by taking into the consideration of the following important factors: (i) AgNPs are able to be in situ self-generated which strongly depends on the structures of reactive components in the used medium, (ii) ability to release silver cations, and (iii) generation of reactive oxygen species such as superoxide, hydrogen peroxide, and hydroxyl radical $[37,38]$. The mechanisms of antimicrobial action of silver ions and $\mathrm{Ag}^{+}$-carrying polymer materials against various microorganisms were studied by many researchers [39-44]. Agreeing with these results, it believed that DNA loses its replication ability and cellular proteins become inactivated on silver caption treatment, as well as $\mathrm{Ag}^{+}$binds to functional groups (i.e., predominantly to carboxyl groups of 
proteins) that leads to the protein denaturation. However, the mechanisms of antimicrobial actions of $\mathrm{Ag}^{+}-$ carrying polymer layered silicate nanocomposites and their Ag-nanoparticles incorporated nanomaterials (polymer coatings and nanofibers) depend on many structural factors including: (1) physical and chemical interfacial interactions of Ag-nanoparticles and functional groups of the polymer matrix with membranes containing DNA and proteins, (2) catalytic effect of $\mathrm{Ag}^{+}$ions and other metal cations from silicate layers in the degradation process of membrane structure, (3) destroying the permeability of the bacterial membranes, (4) depressing the activity of some membranous enzymes, and (5) completely destroying the self-assembled structure of microorganisms. Moreover in our resent study, the antimicrobial and antifungal activity of silver-carrying PVA/ ODA-MMT clay nanofiber composites significantly improved by using organoclay in polymer compositions as a nanofiller because of its high surface area, absorptive and ion exchange capacities, as well as in situ generation of AgNPs from Ag-carrying polymer complexes during electrospinning process as a novel method to synthesize silver nanoparticles onto surface of nanofibers as bioactive platforms [45, 46]. Similar effects of mineral clays were observed for the non-polymer systems contained individual $\mathrm{Ag}^{+}$ and $\mathrm{Cu}^{2+}$ ions [45-47]. However, antimicrobial, antifungal and anticancer properties of the Ag-nanoparticles formed in situ processing during the synthesis and annealing of polymer layered silicate colloidal materials has not been investigated. A combination of wide-range of antimicrobial and anticancer activities of positive charged silver nanoparticles and materials provides their utilization in air filtration, food packaging, cosmetics and bioengineering, especially in tissue engineering, and common nanomedicine applications.

In this work, a new approach have been developed to fabricate colloidal polymer nanomaterial using amphiphilic copolymer-g-PEO/ODA-MMT silicate layered nanocomposite incorporated with silver nanoparticles (AgNPs). in situ generation of AgNPs and their Z-potential and size parameters, as well as nanoparticle distributions were confirmed by UV-Vis spectroscopy and Nanosizer analysis methods. Evaluation of antimicrobial, antifugal and anticancer activities (cytotoxicity, apoptotic and necrotic effects) of colloidal hybrid nanocomposites against G-positive and G-negative bacteria, C. albicans fungal microorganism, and
Fibroblast L929 cells was an important strategy of these investigations.

\section{Experimental}

\subsection{Materials}

Maleic anhydride and 1-dodecene monomers, benzoyl peroxide as a radical initiator and $\alpha, \omega$-hydroxymethoxy-poly(ethylene oxide) ((PEO): $M_{\mathrm{n}}=$ $200 \mathrm{~g} / \mathrm{mol})$ were purchased from Sigma-Aldrich (Germany). Octadecyl amine-montmorillonite (ODAMMT, Nanomer 1.30E, Nanocor Co.) was purchased from Aldrich having the following average parameters: content of ODA surfactant/intercalant $25-30 \%$, particle size $8-10 \mu \mathrm{m}$, bulk density $0.41 \mathrm{~g} / \mathrm{cm}^{3}$ and crystallinity $52.8 \%$ (by XRD) and silver nitrate $\left(\mathrm{AgNO}_{3}, 99.995 \%\right.$, m.p. $202^{\circ} \mathrm{C}$ with decomposition, $d=4.35 \mathrm{~g} / \mathrm{cm}^{3}$ ) was obtained from Sigma-Aldrich (Germany). All other solvents and reagents were of analytical grade and used without purification.

Fibroblast L929 cell line was obtained from the Tissue and Cell Culture Bank of the Foot and Mouth Disease Research Institute (Ankara, Turkey). Cell culture flasks and other plastic material were purchased from Corning (USA). The growth medium, Dulbecco Modified Medium (DMEM) without L-glutamine supplemented with fetal calf serum (FCS), Nutrient Broth (Merck 105443), Mueller-Hilton Agar (Merck 1.05437) and Trypsin-EDTA were purchased from Biological Industries (USA). 2-(4-iodophenyl)-3-(4nitrophenyl)-5-(2,4-disulfo-phenyl)-2H-tetrazolium, monosodium salt (WST-1) was purchased from Roche (Germany). Penicillin (Bioanalyse P10) and tetracyclin (Bioanalyse TE10), Hoechst 33342 and propodium iodide(PI) were purchased from Serva (Israel). Phosphate buffer solution (PBS) was purchased from Sigma-Aldrich (USA). Chemical structures and assignments of all used and synthesized materials were given in Table 1.

\subsection{Synthesis of poly (1-dodecene-alt-MA)}

Amphiphilic alternating copolymer was synthesized by complex-radical copolymerization of maleic anhydride and 1-dodecene (molar ratio $=1: 1$ ) with benzoyl peroxide $(2.5 \%)$ as an initiator in toluene solution at $80^{\circ} \mathrm{C}$ under nitrogen flow up to fully phase separation processing. To prepare copolymer with low molecular mass, higher content of initiator is used in heterogonous solution copolymerization reaction. Selfprecipitated copolymer particles from reaction medium (reaction time $3 \mathrm{~h}$; unlike monomers, copolymer 
Table 1. Chemical structures and estimation of used and synthesized materials.

\begin{tabular}{|l|l|l|l|}
\hline \multicolumn{1}{|c|}{ Materials } \\
\hline $\begin{array}{l}\text { Poly(maleic anhydride-alt-1-dodecene) } \\
\text { copolymer }\end{array}$
\end{tabular}

is not dissolved in toluene) was isolated by filtration and centrifugation, and then was purified by dissolving in acetone and precipitation with methanol. White powder product was dried under vacuum at $40^{\circ} \mathrm{C}$. Molecular mass of the as prepared copolymer is $9.060 \mathrm{~m} / \mathrm{z}$ (by MALDI-TOF MS).

\subsection{Synthesis of nanohybrid composites via grafting and complexing method}

Mixture of $3.5 \mathrm{~g}$ poly(1-dodecene-alt-MA) matrix copolymer and $2.5 \mathrm{~g}$ PEO in 1,4-dioxane solution with $5 \mathrm{wt} \%$ concentration was stirred in carousel type glass microreactor at $40^{\circ} \mathrm{C}$ up to the formation of a viscous liquid. In order to control of the grafting of copolymer with end-hydroxyl group of PEO was carried out with the measurement of acid number values for copolymer and after its esterification with PEO. Then $0.175 \mathrm{~g}$ ODA-MMT clay as reactive nanofiller was dispersed in pure water and added to copolymer- $g$-PEO solution and stirred up to full dispersion and intercalation of copolymer chains between layered silicate galleries. In the last step, various contents (around 0.6-5.0 mass\%) of silver precursor $\left(\mathrm{AgNO}_{3}\right)$ was loaded in reaction medium consisting the copolymer-g-PEO/ODA-MMT nanocomposite with intensive mixing at room temperature up to the formation of Ag-carrying polymer nanocomposite complexes. Colloidal NHCs with different contents of AgNPs were isolated by vacuum evaporation of solvents and annealing of the Ag-carrying polymer complexes at $80^{\circ} \mathrm{C}$ under vacuum for $6 \mathrm{~h}$ due to in situ generation and reductionstabilization of silver nanoparticles onto the PEO branched matrix copolymer. Colloidal structure of NHCs was confirmed by the fact that NHC is not precipitated by methanol from water/dioxane solutions and is not transformed to a solid powder state after annealing. Furthermore, NHCs are able to generate thin film/coating with higher surface adhesion property onto various substrates, and can be easily dissolved in aqueous and physiological medium due to their excellent biocompatibility behavior.

\subsection{Characterization}

The molecular mass of pristne alternating copolymer was performed by matrix-assisted laser desorption/ ionization mass spectrometry (MALDI-TOF MS, Voyager DE PRO model) in THF solution using $\alpha$ ciyano-4-hidroxycinnamic acid (CHCA) as a matrix. UV spectra were performed by Varian Carry 100 model UV-Vis Spectrophotometer using $3 \mathrm{~mL}$ of pure water solutions of NHCs/AgNPs with $0.01 \%$ concentration. The particle size and $\zeta$-potential parameters of nanohybrids were measured by Nanosizer 
3000HSA instrument (Malvern, UK) in water dispersion medium with $0.01 \%$ concentrated sample. Acid numbers ( $\mathrm{AN}$ in $\mathrm{mg}(\mathrm{KOH}) / \mathrm{g}$ ) of alternating copolymer and its PEO grafted derivatives were measured by alkali titration method. To calculate the molar fractions of monomer units and grafting linkage in copolymer, the Equation (1) was used $[48,49]$ :

$$
m_{2}[\mathrm{~mol} \%]=\frac{W_{1}}{\frac{2 M_{\mathrm{KOH}}}{\mathrm{AN}}-\left(W_{2}-W_{1}\right)} \cdot 100
$$

where $W_{1}$ and $W_{2}$ are molecular weights of $m_{1}$ and $m_{2}$ monomer units, $\mathrm{AN}$ is Acid Number $\left[\mathrm{mg}_{\mathrm{KOH}} / \mathrm{g}\right]$ of copolymer and $M_{\mathrm{KOH}}$ is the molecular weight of $\mathrm{KOH}$.

\subsection{Antibacterial and antifungal activity of colloidal hybrid nanocomposites}

Antifungal and antimicrobial activities of the nanohybrid composites were determined according to the methods reported in our earlier research [46].

\subsection{Cytotoxicity of NHCs against L929 fibroblast cells}

The WST-1 assay was used to evaluate cytotoxicity exerted by chemicals. The WST- 1 assay is a simple colorimetric assay to measure cell cytotoxicity, and viability. L929 fibroblast cells were seeded into 96well plates at a density of $5 \cdot 10^{3}$ cells/well and incubated 12 hours. The AgNPs NHC solutions (3.125, $6.25,12.5,25,50$ and $100 \mu \mathrm{g} / \mathrm{mL}$ ) were diluted with cell culture medium and added into the wells and incubated for $48 \mathrm{~h}$ in $\mathrm{CO}_{2}$ incubator. The cell culture medium in each well was then replaced with $100 \mu \mathrm{L}$ of fresh medium and $15 \mu \mathrm{L}$ of WST-1 solution. After incubating for another $4 \mathrm{~h}$ at $37^{\circ} \mathrm{C}$ in a dark condition, the wells were read at $440 \mathrm{~nm}$ using an ELISA plate reader (Biotek), and then the percentage of viable cells was calculated. For WST-1 assay, the control fibroblast cell viability was defined as $100 \%$. The samples were evaluated for each group.

\subsection{Apoptotic and necrotic effects}

Double staining with Hoechst dye $3342(2 \mathrm{mg} / \mathrm{mL})$ and propodium iodide (PI) was applied to quantify the number of apoptotic L929 fibroblast cells $\left(25 \cdot 10^{3}\right.$ cells per well) were seeded into 24-well plates containing DMEM solution. After treating with different concentrations $(3.125,6.25,12.5,25,50,100$ and $200 \mu \mathrm{g} / \mathrm{ml}$ ) of AgNPs incorporated nanohybrid composite (NHC) solution for 48 hours, attached and detached cells were harvested. Upon PBS wash, cells were incubated with Hoechst dye $3342(2 \mathrm{mg} / \mathrm{mL})$, PI $(1 \mathrm{mg} / \mathrm{mL})$ and DNAse free-RNAse $(100 \mathrm{mg} / \mathrm{mL})$ for $15 \mathrm{~min}$ at room temperature. Then, $10-50 \mathrm{~mL}$ of cell suspension was smeared on a glass slide and cover slipped for examination under a fluorescence microscope (Leica, DMI 6000). In double staining method with Hoechst dye and PI, the nuclei of normal cells are stained light blue while apoptotic cells are stained dark blue. The apoptotic cells were identified by their nuclear morphology based on nuclear fragmentation or chromatin condensation. The number of apoptotic and necrotic cells in 10 random microscopic fields were counted. The number of apoptotic and necrotic cells were determined with DAPI and FITC filters of a Fluorescence Inverted Microscope (Leica, Germany). Data were expressed as the ratio of apoptotic or necrotic cells to normal cells. Each group were triplicated.

\section{Results and discussion}

\subsection{Synthetic pathway, chemistry and structure of NHCs}

To synthesize silver nanoparticles (AgNPs) incorporated copolymer-g-PEO layered silicate nanohybrid composites (NHCs), the following steps of synthetic pathways were developed: (1) synthesis of matrix copolymer by complex-radical alternating copolymerization via the formation of electron donor/acceptor type of charge-transfer complex between used 1-dodecene (donor) and maleic anhydride (acceptor) monomers; (2) grafting $\alpha, \omega$-hydroxymethoxy-poly (ethylene oxide) (PEO) onto copolymer through ringopening esterification of anhydride unit with end-hydroxyl group of PEO; (3) intercalating of graft copolymer chains between silicate galleries via in situ interaction of carboxyl and ether groups of graft copolymer with dodecyl amine surfactant-compatibilizer from MMT clay; (4) synthesis of Ag-carrying complexes of copolymer- $g$-PEO with negatively charged graft copolymer by mixing silver precursor $\left(\mathrm{AgNO}_{3}\right)$; (5) in situ reduction/stabilization and generation of AgNPs onto matrix graft copolymer chains by thermal treatment (annealing) of the nanohybrid composites (NHCs) at $80^{\circ} \mathrm{C}$ under vacuum for $6 \mathrm{~h}$. The colloidal NHCs were prepared with different loadings 


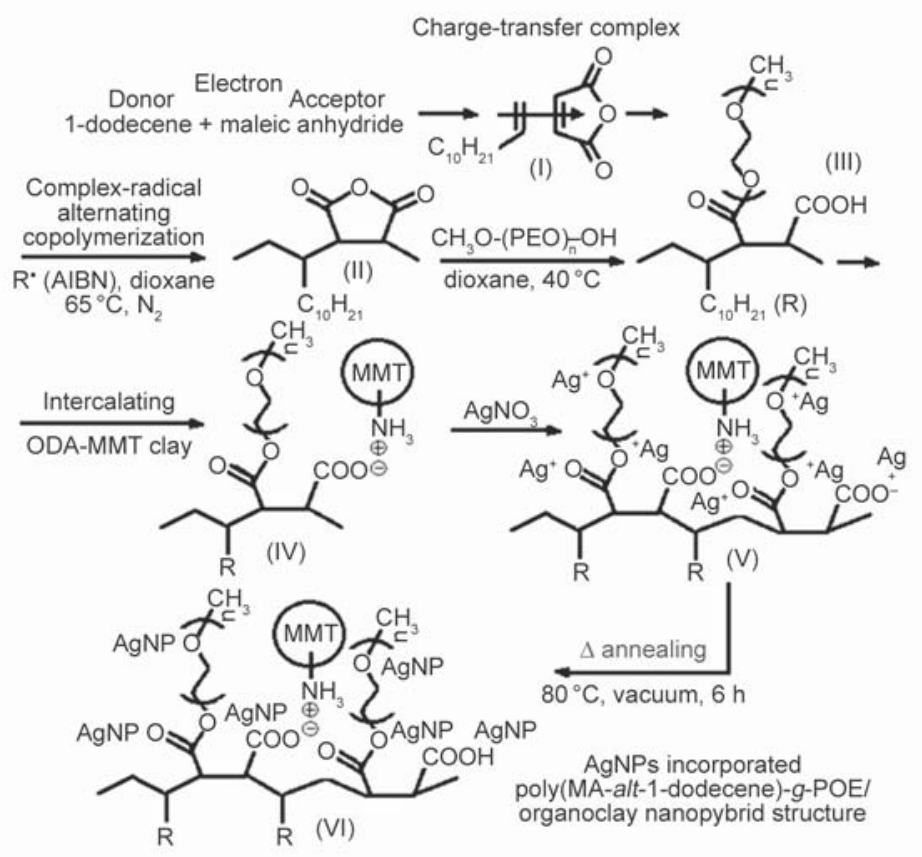

Figure 1. Synthetic pathways, chemistry and structure of NHCs.

of silver precursor $(1.0,2.5,5.0$ and 0.0 mass $\%)$. The above mention synthetic pathways were schematically represented in Figure 1.

As can be seen in Figure 1, the following important steps were assumed: (I) charge-transfer complex formation, (II) complex-radical copolymerization, (III) grafting PEO onto copolymer via esterification, (IV) intercalating the graft copolymers between layered silicate, $(\mathrm{V})$ preparation of Ag-carrying copolymer-g-PEG/organoclay polymer complexes and (VI) in situ generation of AgNPs onto graft copolymer matrix chains by annealing under vacuum.

The molecular mass of alternating copolymer synthesized by complex-radical copolymerization with relatively low molecular mass $(9.060 \mathrm{~m} / \mathrm{z})$ was determined by MALDI-TOF mass spectrometry (Figure 2a). Additionally, the in situ generation of silver nanoparticles onto surface of matrix polymer were confirmed by UV-Vis spectroscopy at $\lambda=417 \mathrm{~nm}$ for the various loading silver precursor $\left(\mathrm{AgNO}_{3}\right.$ salt $)$ in concentration-absorbance relationships manner (Figure 2b).

\subsection{The size and $\zeta$-potential parameters of polymer/AgNPs colloidal nanoparticles}

The results of the $\zeta$-potential and size parameters of nanohybrid particles were given in Figure 3. Agreeing with $\zeta$-potential values and distribution, these particles predominantly show positive charges with a unique distribution. While the size of particles
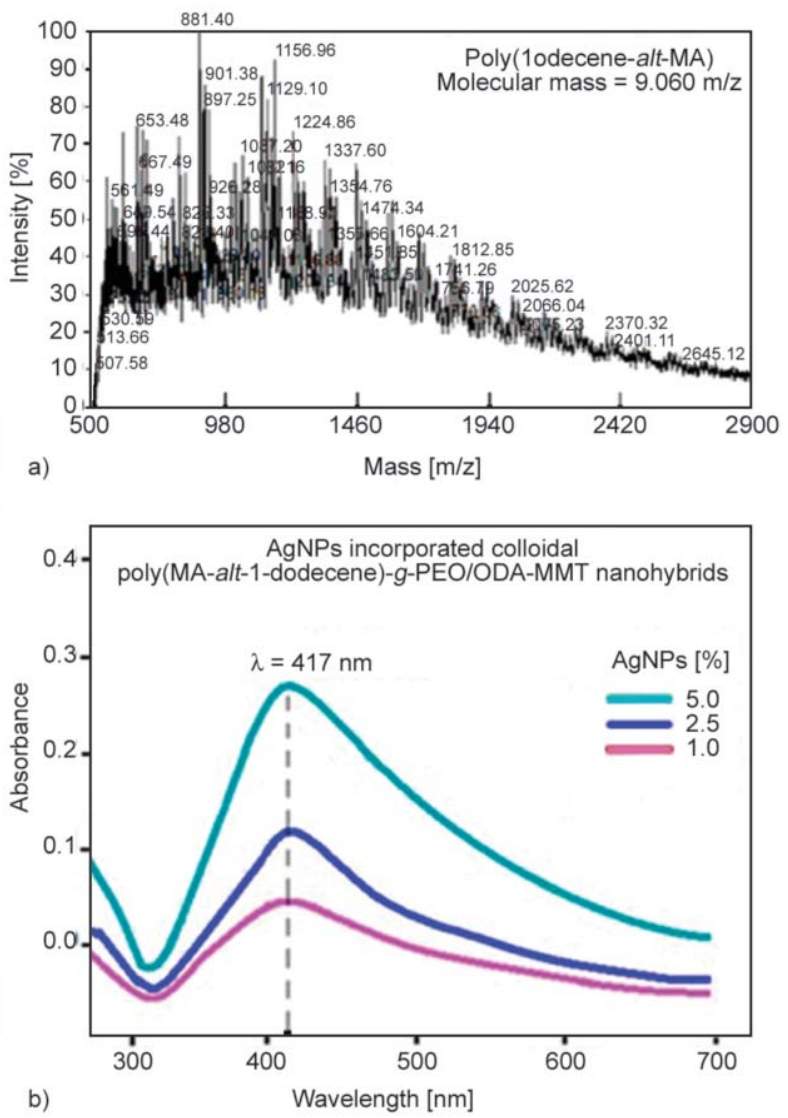

Figure 2. (a) Molecular mass of pristine alternating copolymer by MALDI-TOF mass spectrometry, in tetrahyrofuran (THF) solution using $\alpha$-cyano-4hydroxycinnamic acid (CHCA) as a matrix. (b) UV-Vs spectra of AgNPs incorporated graft copolymer/organoclay nanohybrids. Effect of loading silver precursor. 
show two distribution peaks which are related to silver nanoparticles (first peak at nano-size region around $65--95 \mathrm{~nm}$ ) and layered silicate micro particles (second peak at micro-size region around 500 $600 \mathrm{~nm})$.

Usually, organoclay or intercalated polymer/organoclay exhibited higher size micro particles around 5-8 $\mu \mathrm{m}$. Peak analyses by intensity and volume show average mean values of 145 and $625 \mathrm{~nm}$ and average width values of 50 and $100 \mathrm{~nm}$, respectively. These peak analyses also show average (relative) area values of 36 and 63 for first and second peaks, respectively. The obtained results showed that idal struc- ture of NHCs effectively prevented the swelling process. It was proposed that obtained unique $\zeta$-potential and $\zeta$-size parameters of both silicate layers and silver particles in NHCs can be essentially changed with improving the surface structures of matrix graft copolymer and their bioengineering activity.

\subsection{Antibacterial and antifungal activity of hybrid nanocomposites}

Recent developments in the fabrication of a new class of antifungal functional polymer systems, polymer capsulated nanoparticles, biopolymers, and synthetic polymers functionalized with bioactive groups

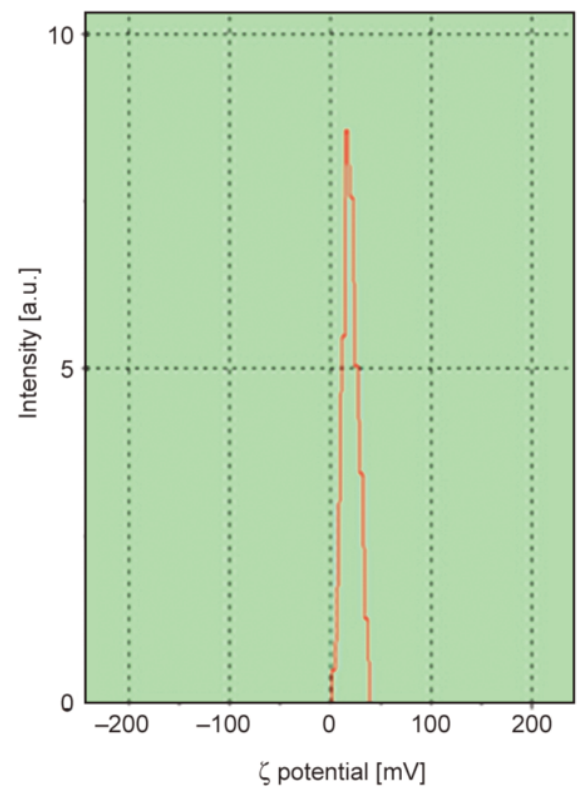

\begin{tabular}{|c|c|c|c|}
\hline Intensity & $\begin{array}{c}\zeta \\
{[\mathrm{mV}]}\end{array}$ & $\begin{array}{c}\text { Mobility } \\
{[\mu \mathrm{mcm} / \mathrm{Vs}]}\end{array}$ & $\begin{array}{c}\text { Frequency } \\
\mathrm{Hz}]\end{array}$ \\
\hline 9.3 & 9.5 & 0.748 & 16.4 \\
\hline 36.4 & 15.9 & 1.247 & 23.3 \\
\hline 32.1 & 22.2 & 1.745 & 30.2 \\
\hline 14.6 & 28.6 & 2.244 & 37.1 \\
\hline 5.4 & 34.9 & 2.743 & 44.0 \\
\hline \multicolumn{5}{|c|}{ Peak analysis by zeta potential } \\
\hline Peak & Amp & Mean & Wirth \\
\hline 1 & 100.0 & 19.1 & 3.5 \\
\hline \multicolumn{5}{|c|}{ Peak analysis by mobility } \\
\hline Peak & Amp & Mean & Wirth \\
\hline 1 & 100.0 & 1.5 & 0.3 \\
\hline \multicolumn{5}{|c|}{ Peak analysis by frequency } \\
\hline Peak & Amp & Mean & Wirth \\
\hline 1 & 100.0 & 27.6 & 3.8 \\
\hline
\end{tabular}

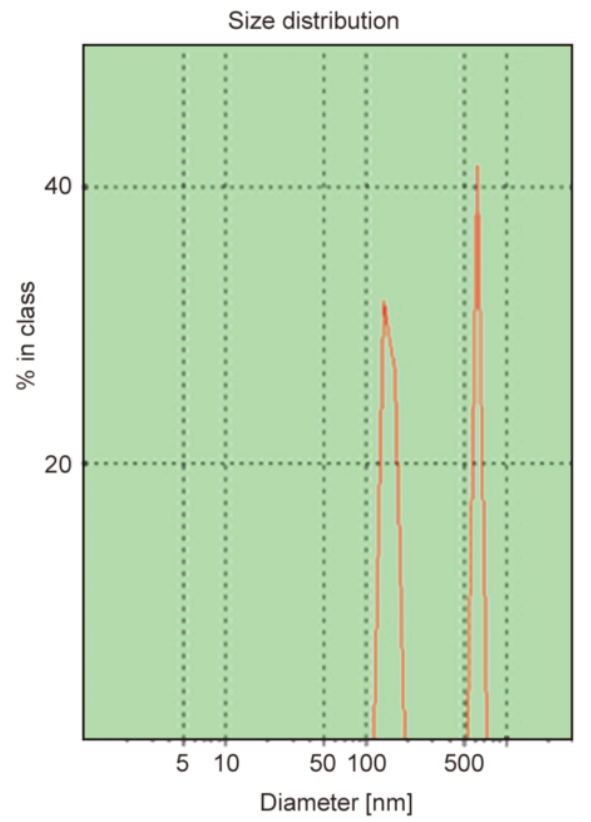

\begin{tabular}{|c|c|c|c|}
\hline \multicolumn{5}{|c|}{ Peak analysis by intensity } \\
\hline Peak & Amp & Mean & Wirth \\
\hline 1 & 58.8 & 146.2 & 47.5 \\
\hline 2 & 41.5 & 623.2 & 106.5 \\
\hline \multicolumn{4}{|c|}{ Peak analysis by volume } \\
\hline Peak & Amp & Mean & Wirth \\
\hline 1 & 14.7 & 144.8 & 58.1 \\
\hline 2 & 85.3 & 627.8 & 97.5 \\
\hline \multicolumn{4}{|c|}{ Peak analysis by number } \\
\hline 1 & Amp & Mean & Wirth \\
\hline 2 & 93.6 & 142.1 & 54.5 \\
\hline
\end{tabular}

Figure 3. The $\zeta$-potential and size parameters of colloidal NHC/AgNPs nanohydrid prepared in the presence of 2.5 mass $\%$ of silver precursor. 
have indicated that these systems can be successfully utilized as biocides in many areas, especially in medicine and pharmacy. Recently, in our previous study, we reported the higher antimicrobial and antifungal activity of multifunctional Ag-carrying PVA-based nanofiber composites [46]. In this work, antibacterial and antifungal studies were carried out with novel copolymer- $g$-PEO/Organoclay/AgNPs idal nanohybrid composites using G-positive (Staphylococcus aureus Newman, P. aeruginosa) and G-negative (Escherichia coli 25922 and P. aeruginosa PA01) bacteria, as well as a Candida albicans 10231 fungal microorganism obtained from TOBB ETU-Hospital (Turkey). Cell culture flasks, disks, and other medical plastic materials were purchased from Corning. The results of antibacterial and antifungal activity via diameter of distribution zone were given in Figures 4 and 5a. Agreeing with these results, bioactivity of the nanohybrid composites strongly depend on the concentration (1.0 mass $\%$ for NHC-1, 2.5 mass $\%$ for NHC-2, 5.0 mass $\%$ for NHC-3, and 0.0 mass $\%$ for NHC-0) of incorporated silver precursor $\left(\mathrm{AgNO}_{3}\right)$ and in situ generated AgNPs during annealing. Higher effects of loading (changes from 6.5 to $16 \mathrm{~mm}$ of zone and from 15 to $20 \mathrm{~mm}$ of zone) were observed for the interactions of nanohybrid composites with P. aeruginosa and S. aureus Newman bacteria, respectively. While interactions with E.coli 25922 and P. aeruginosa PA01 bacteria, as well as with C. albicans 10231 fungal (Figure 5a) accompanied a visible changes of diameter of zones. The lower inhibition effects of the copolymer-g-PEO/ODA-MMT clay composites, which is not contained AgNPs, on microorganisms (S. aureus Newman and P. aeruginosa PA01) can be explained by a complexed colloidal structure of matrix polymer layered silicate via hydroxyl (carboxyl)-amine physical interactions and partial swelling process, as well as formation of microdomains with lower bioactive surface contact area.

Antibacterial properties of AgNPs were also determined in bacterial disk using G-negative E. coli and tetracycline antibiotic for comparative analysis. The results were obtained from microscope photographs by conventional disk diffusion assay in which the antibacterial feature of different percentage AgNPs solution were given in Figure 5b.

The results obtained of antibacterial zones (around the disk) were given in table of Figure 5b. As seen in these dishes, the disk diameter increases when the percentage of AgNPs is increased on S. aureus culture. Comparative analysis of antibacterial disk diameters of E.coli and known antibiotic (tetracycline) indicated that the disk diameters show the same time effects, i.e., disk diameters for the both type of cell cultures are almost not changed.

\subsection{Cytotoxicity results}

The toxic effect of the polymer nanohybrid composites was determined by WST-1 method on the fibroblast cell line and the results are given in Figure 6. The effects of nanohybrid composites (NHC-1, NHC2.5 and NHC-5) to the cells were evaluated with different concentrations of AgNPs (1, 2.5 and 5\%) and only medium without AgNPs (NHC-0) was used as a control group. According to the obtained results, toxic effect strongly depends on the loading AgNPs and and toxicity of NHCs increases in increasing concentration of samples. It was found that toxic effects of all NHCs were similar to each other, and relative highest toxic effect was obtained for NHC-5 at $200 \mu \mathrm{g} / \mathrm{mL}$ concentration.

\subsection{Apoptotic and necrotic results}

The apoptotic and necrotic effects of AgNPs (NHC1, NHC-2.5 and NHC-5) were determined by double staining method and the results obtained are given in Table 2. Agreeing with these results, the apoptotic and necrotic effects strongly depend on the concentration of Ag-NPs. The highest apoptotic effect was also obtained for the NHC-5 composite against fibroblast cells. When NHC-5 was administered to the cells at $200 \mu \mathrm{g} / \mathrm{mL}$ concentration, an apoptotic index of $16 \pm 0.5 \%$ was obtained. It was found that by increasing the matter concentration, necrotic effect also increased. The highest necrotic effect (index $24 \pm 1.2 \%$ ) was obtained for NHC-5 sample at $200 \mu \mathrm{g} / \mathrm{mL}$ concentration in parallel to the toxicity results.

Agreeing with these results, the mechanisms of antimicrobial actions of $\mathrm{Ag}^{+}$-carrying polymer layered silicate nanocomposites and their Ag-nanoparticles incorporated nanomaterials (polymer coatings and nanofibers), as well as polymer/AgNPs hybrids, depend on several structural factors. These parameters are listed as below: (1) physical and chemical interfacial interactions of Ag-nanoparticles and functional groups of the polymer matrix with membranes containing DNA and proteins, (2) catalytic effect of $\mathrm{Ag}^{+}$ ions and other metal cations from silicate layers in 


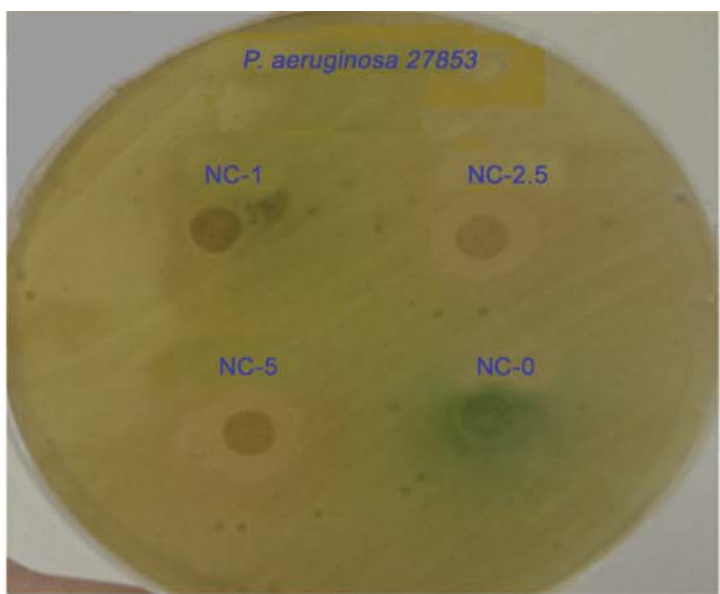

Pseudomonas aeruginosa

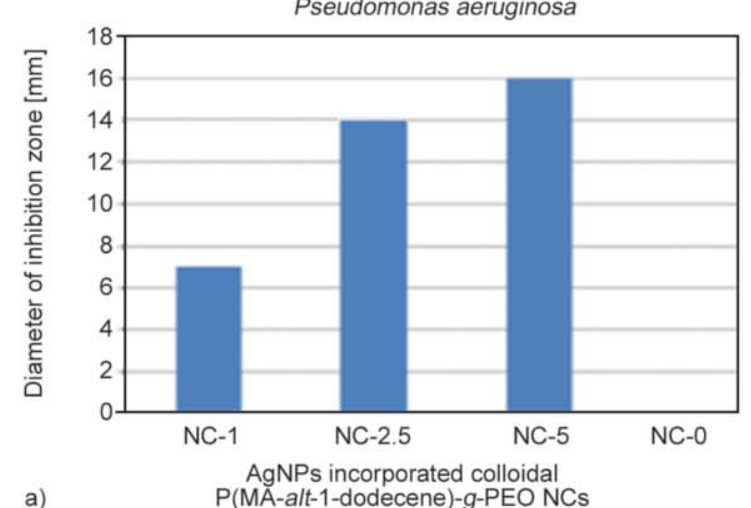

a)
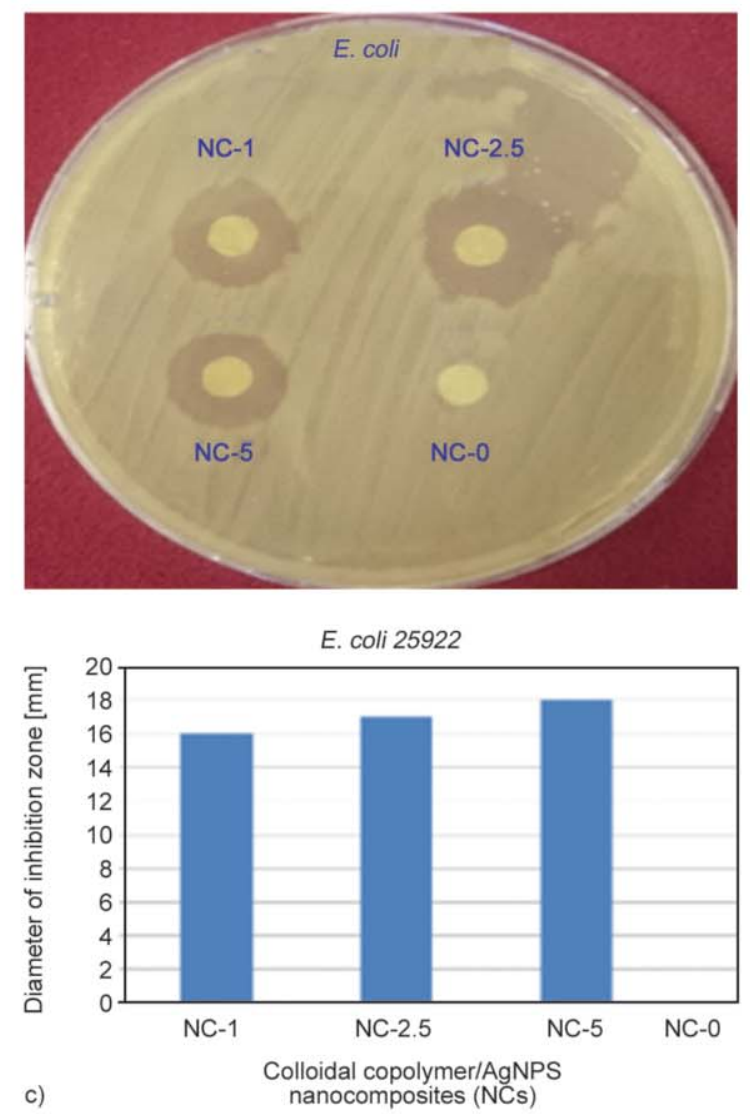

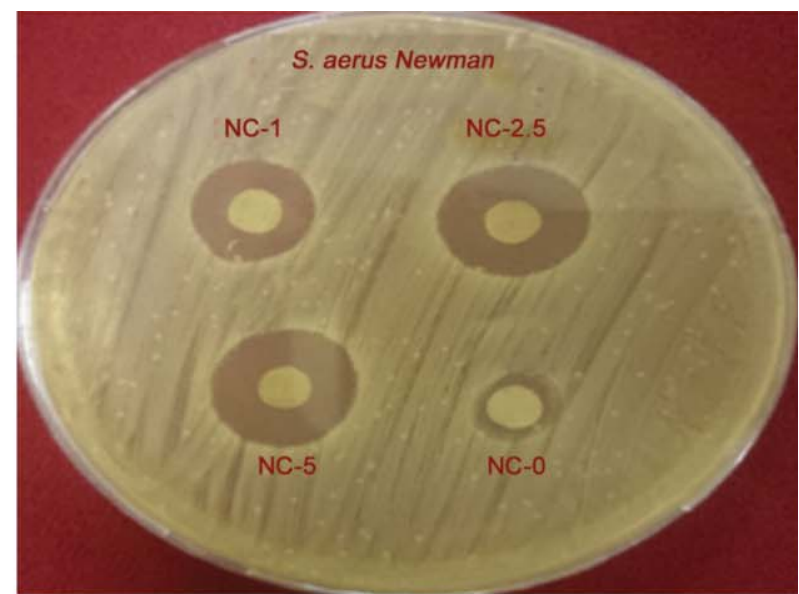

Staphylococcus aureus Newman
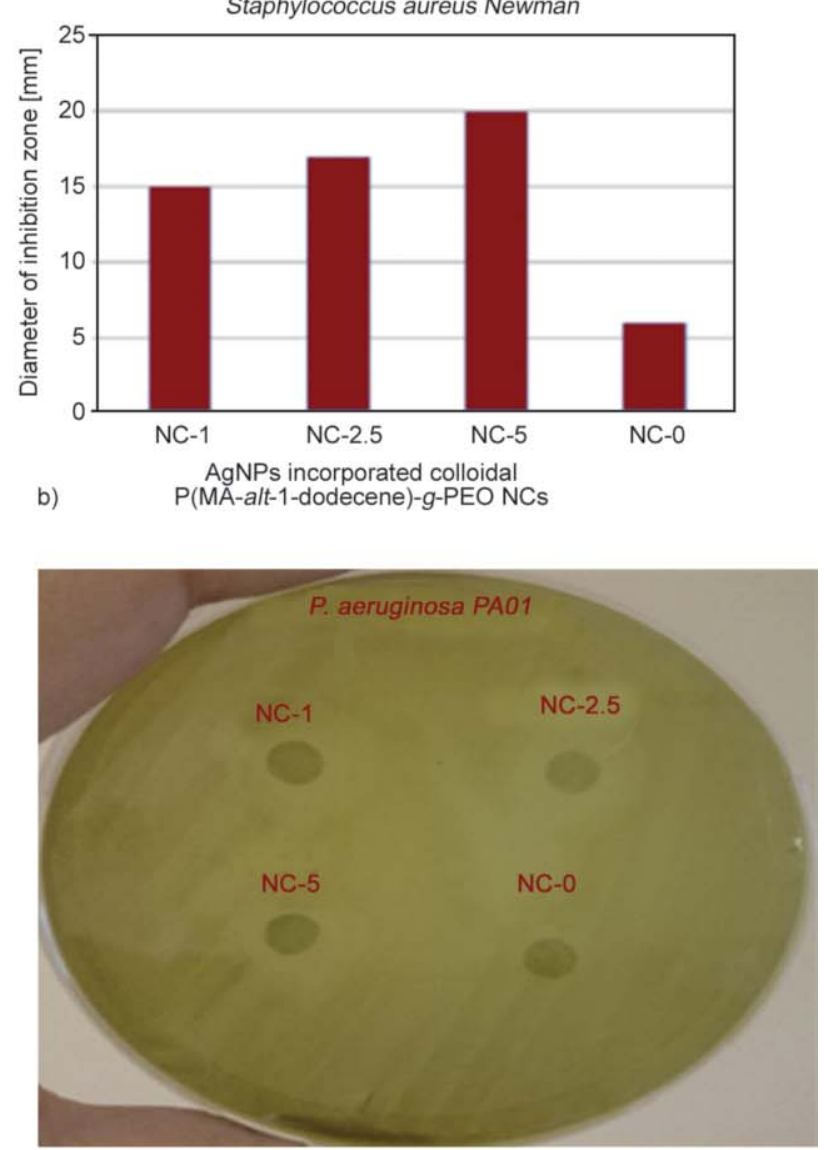

Pseudomonas aeruginosa PA01

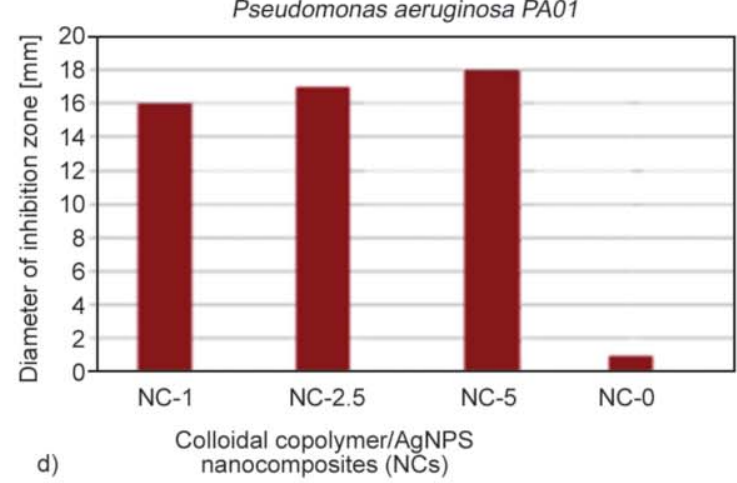

d) nanocomposites (NCs)

Figure 4. Antibacterial activity of AgNPs (NC-0: 0.0 mass \%; NC-1: 1.0 mass \%; NC-2.5: 2.5 mass \%; NC-5: 5.0 mass $\%$ ) incorporated colloidal poly(MA-alt-1-dodecene)- $g$-PEO/ODA-MMT nanocomposites. 

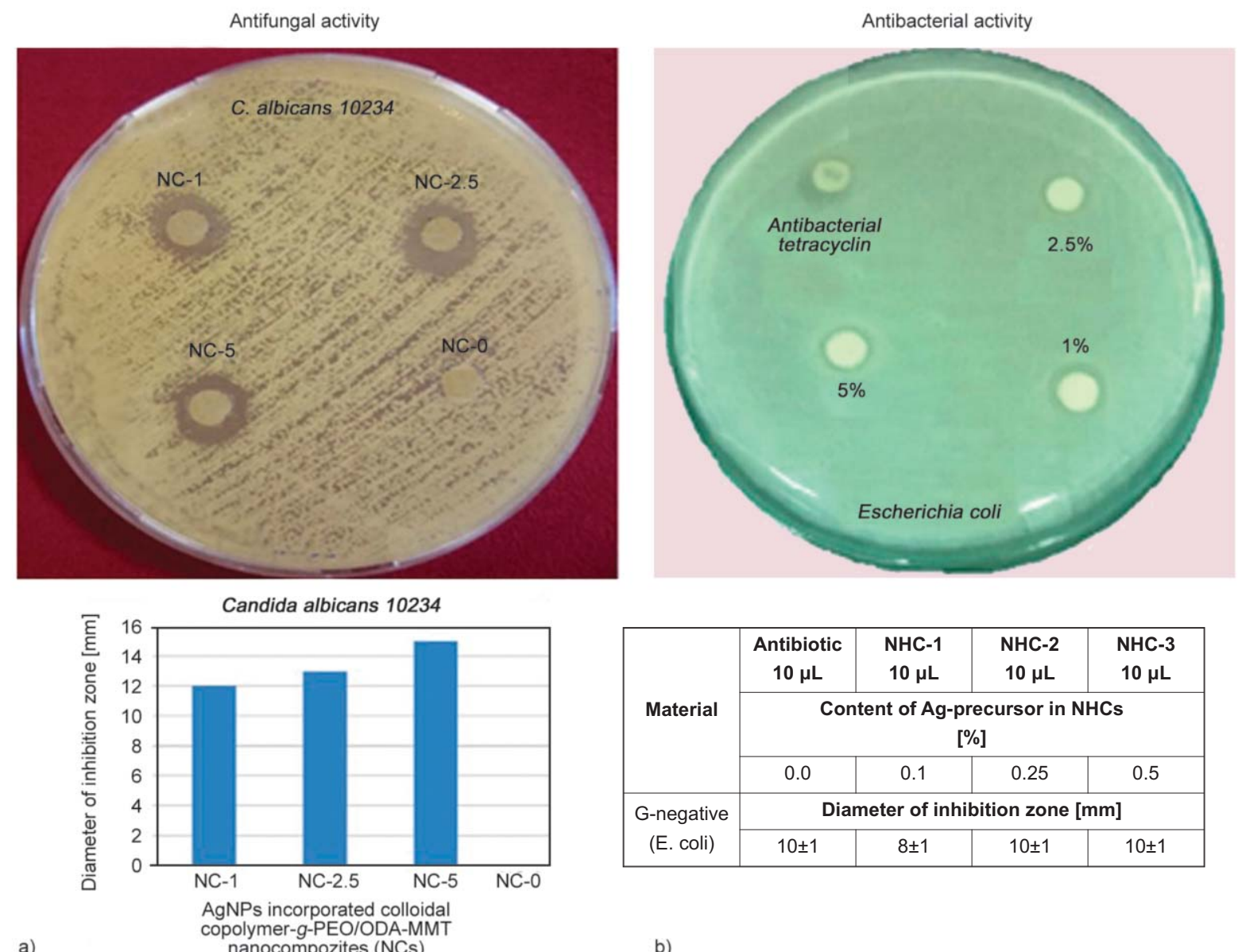

\begin{tabular}{|c|c|c|c|c|}
\hline \multirow{4}{*}{ Material } & $\begin{array}{c}\text { Antibiotic } \\
10 \mu \mathrm{L}\end{array}$ & $\begin{array}{c}\text { NHC-1 } \\
10 \mu \mathrm{L}\end{array}$ & $\begin{array}{c}\text { NHC-2 } \\
10 \mu \mathrm{L}\end{array}$ & $\begin{array}{c}\text { NHC-3 } \\
10 \mu \mathrm{L}\end{array}$ \\
\cline { 2 - 5 } & \multicolumn{4}{|c|}{ Content of Ag-precursor in NHCs } \\
& 0.0 & 0.1 & 0.25 & 0.5 \\
\cline { 2 - 5 } & 0.0 & \multicolumn{4}{|c|}{ Diameter of inhibition zone [mm] } \\
\hline \multirow{2}{*}{$\begin{array}{c}\text { G-negative } \\
\text { (E. coli) }\end{array}$} & $10 \pm 1$ & $8 \pm 1$ & $10 \pm 1$ & $10 \pm 1$ \\
\cline { 2 - 5 } & &
\end{tabular}

a) nanocompozites (NCs)

b)

Figure 5. (a) Antifungal activity of AgNPs incorporated (1.0, 2.5 and 5.0 mass\%) copolymer-g-PEO/ODA-MMT nanocomposites. (b) Antibacterial activities of the colloidal NHCs consisting different amounts of silver precursor $(0.1$, 0.25 and 0.5 mass $\%$ in NHC-0, NHC-1, NHC-2 and NHC-3) and tetracycline antibiotic against E.coli.

the degradation process of membrane structure, (3) destroying the permeability of the bacterial membranes, (4) depressing the activity of some membranous enzymes, and (5) completely destroying the self-assembled DNA structure of microorganisms.

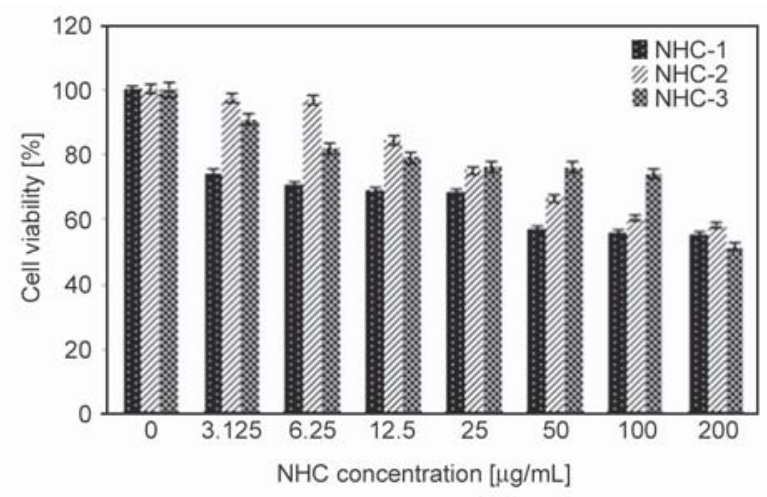

Figure 6. Fibroblast cell viability after incubation with different concentrations (around 3.125-200 $\mu \mathrm{g} / \mathrm{mL}$ ) of nanohybrid compositions (NHCs) incorporated with various amounts in situ generated AgNPs from carried silver nitrate precursor $(1,2.5$ and $5 \%$ ). Data given as mean \pm std.

\section{Conclusions}

This work presents a new approach to synthesize of the colloidal ODA-MMT-poly(MA-alt-1-dodecene)$g$ - $\alpha, \omega$-methoxyhydroxyl-PEO/silver nanoparticles (AgNPs) nanohybrid composites (NHCs) using the following synthetic pathways: (1) complex-radical alternating copolymerization of maleic anhydride with 1 -dodecene $\alpha$-olefin comonomer, (2) grafting PEO onto alternating copolymer through ring-opening esterification, (3) intercalating a copolymer- $g$-PEO between organoclay layers via complex formation of maleate carboxyl with octadecyl amine, and (4) in situ generation of AgNPs in polymer nanocomposite by annealing method under vacuum. An important strategy of these investigations is the evaluation of antimicrobial, antifungal and anticancer activities (cytotoxicity, apoptotic and necrotic effects) of colloidal hybrid nanocomposites against G-positive and Gnegative bacteria, $C$. albicans fungal microorganism, and Fibroblast L929 cells. The synthesized AgNPs incorporated biocompatible and bioactive colloidal 
Table 2. Apoptotic and necrotic index in fibroblast L929 cells of ODA-MMT-copolymer- $g$-PEO/AgNPs nanohybrid composites (NHC-1, 2 and 3). Data obtained by double staining methods for the various concentrations of NHCs. The percent data were given as mean \pm std.

\begin{tabular}{|c|c|c|c|c|c|c|}
\hline \multirow{2}{*}{$\begin{array}{c}\text { NHCs } \\
{[\mathbf{\mu g} / \mathbf{m L}]}\end{array}$} & \multicolumn{2}{|c|}{ NHC-1 } & \multicolumn{2}{c|}{ NHC-2 } & \multicolumn{2}{c|}{ NHC-3 } \\
\cline { 2 - 7 } & $\begin{array}{c}\text { Apoptotic index } \\
{[\%]}\end{array}$ & $\begin{array}{c}\text { Necrotic index } \\
{[\%]}\end{array}$ & $\begin{array}{c}\text { Apoptotic index } \\
{[\%]}\end{array}$ & $\begin{array}{c}\text { Necrotic index } \\
{[\%]}\end{array}$ & $\begin{array}{c}\text { Apoptotic index } \\
{[\%]}\end{array}$ & $\begin{array}{c}\text { Necrotic index } \\
{[\%]}\end{array}$ \\
\hline 0.000 & $1.0 \pm 1.0$ & $1.5 \pm 0.5$ & $1.0 \pm 1.0$ & $1.5 \pm 0.5$ & $1.0 \pm 1.0$ & $1.5 \pm 0.5$ \\
\hline 3.125 & $2.0 \pm 1.4$ & $10.0 \pm 0.4$ & $4.0 \pm 1.0$ & $4.0 \pm 0.2$ & $4.0 \pm 0.5$ & $10.5 \pm 0.3$ \\
\hline 6.250 & $5.5 \pm 0.4$ & $12.5 \pm 0.3$ & $5.0 \pm 0.6$ & $6.0 \pm 1.0$ & $5.0 \pm 1.4$ & $12.0 \pm 0.5$ \\
\hline 12.500 & $7.0 \pm 0.2$ & $14.5 \pm 1.5$ & $5.5 \pm 2.0$ & $12.0 \pm 0.3$ & $7.0 \pm 0.7$ & $13.0 \pm 0.8$ \\
\hline 25.000 & $8.5 \pm 0.7$ & $18.0 \pm 1.0$ & $6.0 \pm 0.5$ & $14.0 \pm 1.4$ & $9.5 \pm 1.0$ & $16.5 \pm 0.7$ \\
\hline 50.000 & $11.0 \pm 1.0$ & $20.0 \pm 0.4$ & $9.0 \pm 0.2$ & $16.5 \pm 0.7$ & $10.0 \pm 0.2$ & $19.0 \pm 1.5$ \\
\hline 100.000 & $13.0 \pm 1.5$ & $21.5 \pm 1.2$ & $12.0 \pm 1.5$ & $18.0 \pm 0.5$ & $11.0 \pm 0.5$ & $21.5 \pm 1.0$ \\
\hline 200.000 & $16.0 \pm 0.5$ & $23.0 \pm 0.5$ & $13.0 \pm 0.3$ & $20.0 \pm 1.5$ & $13.5 \pm 1.0$ & $24.0 \pm 1.2$ \\
\hline
\end{tabular}

NHCs are promising candidate for a wide-range of applications in air filtration, food packaging systems, bioengineering, especially in pharmacy, tissue regeneration and nanomedicine.

\section{Acknowledgements}

The authors thank the Turkish Scientific and Technological Research Council (TUBITAK) and Hacettepe University (HU) Scientific Research Unit for the financial support of this work through postdoctoral projects TBAG-HD/249 and HU-BAP-60808 (No. 014d01601003), respectively.

\section{References}

[1] Muñoz-Bonilla A., Fernández-García M.: The roadmap of antimicrobial polymeric materials in macromolecular nanotechnology. European Polymer Journal, 65, 46-62 (2015). https://doi.org/10.1016/j.eurpolymj.2015.01.030

[2] Muñoz-Bonilla A., Fernández-García M.: Polymeric materials with antimicrobial activity. Progress in Polymer Science, 37, 281-339 (2012).

https://doi.org/10.1016/j.progpolymsci.2011.08.005

[3] Álvarez-Paino M., Muñoz-Bonilla A., Fernández-García M.: Antimicrobial polymers in the nano-world. Nanomaterials, 7, 48-92 (2017). https://doi.org/10.3390/nano7020048

[4] Ren W., Cheng W., Wang G., Liu Y.: Developments in antimicrobial polymers. Journal of Polymer Science, Part A: Polymer Chemistry, 55, 632-639 (2017). https://doi.org/10.1002/pola.28446

[5] Wang Y., Gong X.: Superhydrophobic coatings with periodic ring structured patterns for self-cleaning and oilwater separation. Advanced Materials Interfaces, 4, 1700190/1-1700190/8 (2017).

https://doi.org/10.1002/admi.201700190

[6] Wang Y., Gong X.: Special oleophobic and hydrophilic surfaces: Approaches, mechanisms, and applications. Journal of Materials Chemistry A, 5, 3759-3773 (2017). https://doi.org/10.1039/C6TA10474F
[7] Marambio-Jones C., Hoek E.: A review of the antibacterial effects of silver nanomaterials and potential implications for human health and the environment. Journal of Nanoparticle Research, 12, 1531-1551 (2010). https://doi.org/10.1007/s11051-010-9900-y

[8] Aral O., Buyukacinci C., Rzayev Z.: Multilayer oriented antimicrobial and antifogging films. U.S. Patent 7,097,912 B2, USA (2006).

[9] Shawson R. M., Van Dyke M. I., Lee H., Trevors J. T.: Germanium and silver resistance, accumulation, and toxicity in microorganisms. Plasmid, 27, 72-79 (1992). https://doi.org/10.1016/0147-619X(92)90008-X

[10] Zhao G. J., Stevens S. E.: Multiple parameters for the comprehensive evaluation of the susceptibility of EScherichia coli to the silver ion. Biometals, 11, 27-32 (1998).

https://doi.org/10.1023/A:1009253223055

[11] Sondi I., Salopek-Sondi B.: Silver nanoparticles as antimicrobial agent: A case study on E. coli as a model for Gram-negative bacteria. Journal of Colloid and Interface Science, 275, 177-182 (2004). https://doi.org/10.1016/j.jcis.2004.02.012

[12] Herrera M., Carrión P., Baca P., Liébana J., Castillo A.: In vitro antibacterial activity of glass-ionomer cements. Microbios, 104, 141-148 (2001).

[13] Bosseti M., Massé A., Tobin E., Cannas M.: Silver coated materials for external fixation devices: In vitro biocompatibility and genotoxicity. Biomaterials, 23, 887892 (2002). https://doi.org/10.1016/S0142-9612(01)00198-3

[14] Aymonier C., Schlotterbeck U., Antonietti L., Zacharias P., Thomann R., Tiller J. C., Mecking S.: Hybrids of silver nanoparticles with amphiphilic hyperbranched macromolecules exhibiting antimicrobial properties. Chemical Communication, 24, 3018-3019 (2002). https://doi.org/10.1039/b208575e

[15] Moyer C. A.: A treatment of burns. Transactions and Studies of the College of Physicians of Philadelphia, 33, 53-103 (1965). 
[16] Yang Y., Matsubara S., Xiong L., Hayakawa T., Nogami M.: Solvothermal synthesis of multiple shapes of silver nanoparticles and their SERS properties. Journal of Physical Chemistry C, 111, 9095-9104 (2007). https://doi.org/10.1021/jp068859b

[17] Salkar R. A., Jeevanandam P., Aruna S. T., Koltypin Y., Gedanken A.: The sonochemical preparation of amorphous silver nanoparticles. Journal of Materials Chemistry, 9, 1333-1335 (1999).

https://doi.org/10.1039/A900568D

[18] Lee P. C., Merisel D.: Adsorption and surface-enhanced Raman of dyes on silver and gold sols. Journal of Physical Chemistry, 86, 3391-3395 (1982).

https://doi.org/10.1021/j100214a025

[19] Dolgaev S. I., Simakin A.V., Voronov V. V., Shafeev G. A., Bozon-Verduraz F.: Nanoparticles produced by laser ablation of solids in liquid environment. Applied Surface Science, 186, 546-551 (2002).

https://doi.org/10.1016/S0169-4332(01)00634-1

[20] Naik R. R., Stringer S. J., Agarwal G., Jones S. E., Stone M. O.: Biomimetic synthesis and patterning of silver nanoparticles. Nature Materials, 1, 169-172 (2002). https://doi.org/10.1038/nmat758

[21] Shankar S. S., Rai A., Ahmad A., Sastry M.: Rapid synthesis of Au, Ag, and bimetallic Au core-Ag shell nanoparticles using Neem (Azadirachta indica) leaf broth. Journal of Colloid and Interface Science, 275, 496-502 (2004). https://doi.org/10.1016/j.jcis.2004.03.003

[22] Fu M., Li Q., Sun D., Lu H., Deng X., Wang H., Huang J.: Rapid preparation process of silver nanoparticles by bioreduction and their characterizations. Chinese Journal of Chemical Engineering, 14, 114-117 (2006). https://doi.org/10.1016/S1004-9541(06)60046-3

[23] Balaji S., Basavaraja S., Deshpande R., Mahesh D. B., Prabhakar B. K., Venkataraman A.: Extracellular biosynthesis of functionalized silver nanoparticles by strains of Cladosporium cladosporioides fungus. Colloids and Surfaces B: Biointerfaces, 68, 88-92 (2009). https://doi.org/10.1016/j.colsurfb.2008.09.022

[24] Ilker M. F., Nüsslein K., Tew G. N., Coughlin E. B.: Tuning the hemolytic and antibacterial activities of amphiphilic polynorbornene derivatives. Journal of the American Chemical Society, 126, 15870-15875 (2004). https://doi.org/10.1021/ja045664d

[25] Sambhy V., MacBride M. M., Peterson B. R., Sen A.: Silver bromide nanoparticle/polymer composites: Dual action tunable antimicrobial materials. Journal of the American Chemical Society, 128, 9798-9808 (2006). https://doi.org/10.1021/ja061442z

[26] Melaiye A., Sun Z., Hindi K., Milsted A., Ely D., Reneker D., Tessier C. A., Youngs W.: Silver(I)-1midazole cyclophane gem-diol complexes encapsulated by electrospun tecophilic nanofibers: Formation of nanosilver particles and antimicrobial activity. Journal of the American Chemical Society, 127, 2285-2291 (2005).

https://doi.org/10.1021/ja040226s
[27] Ho C. H., Tobis J., Christina S., Thoman R., Tiller J. C.: Nanoseparated polymeric networks with multiple antimicrobial properties. Advanced Materials, 16, 957961 (2004). https://doi.org/10.1002/adma.200306253

[28] Rosato A. E., Tallent S. M., Edmond M. B., Bearman G. M.: Susceptibility of coagulase-negative staphylococcal nosocomial bloodstream isolates to the chlorhexidine/silver sulfadiazine-impregnated central venous catheter. American Journal of Infection Control, 32, 486-488 (2004). https://doi.org/10.1016/S0196655304004754

[29] Allain L. R., Vo-Dinh T.: Surface-enhanced Raman scattering detection of the breast cancer susceptibility gene $B R C A 1$ using a silver-coated microarray platform. Analytica Chimica Acta, 469, 149-154 (2002). https://doi.org/10.1016/S0003-2670(01)01537-9

[30] Muraca D., Sharma S. K., Socolovsky L. M., de Siervo A., Lopes G., Pirota K. P.: Influence of silver concentrations on structural and magnetic properties of $\mathrm{Ag}-\mathrm{Fe}_{3} \mathrm{O}_{4}$ heterodimer nanoparticles. Journal of Nanoscience and Nanotechnology, 12, 6961-6967 (2012). https://doi.org/10.1166/jnn.2012.6155

[31] Park Y., Noh H-J., Han L., Kim H-S., Kim Y-J., Choi J. S., Kim C-K., Kim Y-S., Cho S.: Artemisia capillaris extracts as a green factory for the synthesis of silver nanoparticles with antibacterial activities. Journal of Nanoscience and Nanotechnology, 12, 7087-7095 (2012).

https://doi.org/10.1166/jnn.2012.6575

[32] Nomiya K., Takahashi S., Noquchi R.: Synthesis and crystal structure of three silver(I) complexes with (S)(+)-5-oxo-2-tetrahydrofurancarboxylic acid (S-Hothf) and its isomeric forms (R-Hothf and R,S-Hothf) showing wide spectra of effective antibacterial and antifungal activities. Chiral helical polymers in the solid state formed by self-assembly of the dimeric $[\mathrm{Ag}(\text { othf })]_{2}$ cores. Journal of the Chemical Society, Dalton Transactions, 0, 1343-1348 (2000). https://doi.org/10.1039/a910251p

[33] Nomiya K., Takahashi S., Noquchi R., Nemoto S., Takayama T., Oda M.: Synthesis and characterization of water-soluble silver(I) complexes with L-histidine ( $\mathrm{H}_{2}$ his) and (S)-(-)-2-pyrrolidone-5-carboxylic acid ( $\mathrm{H}_{2}$ pyrrld) showing a wide spectrum of effective antibacterial and antifungal activities. Crystal structures of chiral helical polymers $[\mathrm{Ag}($ Hhis $)] \mathrm{n}$ and $\left\{[\mathrm{Ag}(\mathrm{Hpyrrld})]_{2}\right\}_{\mathrm{n}}$ in the solid state. Inorganic Chemistry, 24, 3301-3311 (2000).

https://doi.org/10.1021/ic990526o

[34] Nam S., Parikh D. V., Condon B. D., Zhao Q., Yoshkova-Tarver M.: Importance of poly(ethylene glycol) conformation for the synthesis of silver nanoparticles in aqueous solution. Journal of Nanoparticle Research, 13, 3755-3764 (2011). https://doi.org/10.1007/s11051-011-0297-z 
[35] Rzayev Z. M. O., Şenol B., Denkbaş A. B.: Functional copolymer/organo-montmorillonite nanoarchitectures. IX. Synthesis and nanostructure-morphology-thermal behaviour relationships of poly[(maleic anhydride)-alt(acrylic acid)]/organo-montmorillonite nanocomposites. Polymer International, 60, 1446-1454 (2011). https://doi.org/10.1002/pi.3099

[36] Peppas N. A., Tennenhouse D.: Semicrystalline poly (vinyl alcohol) films and their blends with poly(acrylic acid) and poly(ethylene glycol) for drug delivery applications. Journal of Drug Delivery Science and Technology, 14, 291-297 (2004).

https://doi.org/10.1016/S1773-2247(04)50050-3

[37] Kim J. S., Kuk E., Yu K. N., Kim J-H., Park J. H., Lee H. J., Kim S. H., Park Y. K., Park Y. H., Hwang C-Y., Kim Y-K., Lee Y-S., Jeong D. H., Cho M-N.: Antimicrobial effects of silver nanoparticles. Nanomedicine: Nanotechnology, Biology and Medicine, 3, 95-101 (2007).

https://doi.org/10.1016/j.nano.2006.12.001

[38] Le Pape H., Solano-Serena F., Contini P., Devillers C., Maftah A., Leprat P.: Involvement of reactive oxygen species in the bactericidal activity of activated carbon fibre supporting silver: Bactericidal activity of $\mathrm{ACF}(\mathrm{Ag})$ mediated by ROS. Journal of Inorganic Biochemistry, 98, 1054-1060 (2004).

https://doi.org/10.1016/j.jinorgbio.2004.02.025

[39] Spadaro J. A., Berger T. J., Barranco S. D., Shapin S. E., Becker R. O.: Antibacterial effects of silver electrodes with weak direct current. Antimicrobial Agents and Chemotherapy, 6, 637-642 (1974). https://doi.org/10.1128/AAC.6.5.637

[40] Li W-R., Xie X-B., Shi Q-S., Zeng H-Y., Yang Y-S., Chen Y-B.: Antibacterial activity and mechanism of silver nanoparticles on Escherichia coli. Applied Microbiology and Biotechnology, 85, 1115-1122 (2010). https://doi.org/10.1007/s00253-009-2159-5

[41] Valappil S. P., Knowles J. Wilson C., M.: Effect of silver-doped phosphate-based glasses on bacterial biofilm growth. Applied and Environmental Microbiology, 74, 5228-5230 (2008). https://doi.org/10.1128/AEM.00086-08

[42] Valappil S. P., Pickup D. M., Carroll D. L., Hope C. K., Pratten J., R. Newport J., Smith M. E., Wilson M., Knowles J. C.: Effect of silver content on the structure and antibacterial activity of silver-doped phosphatebased glasses. Antimicrobial Agents and Chemotherapy, 51, 4453-4461(2007).

https://doi.org/10.1128/AAC.00605-07
[43] Lara H. H., Ayala-Nuñez N. V., del Carmen Ixtepan Turrent L., Padilla C. R.: Bactericidal effect of silver nanoparticles against multidrug-resistant bacteria. World Journal of Microbiology and Biotechnology, 26, 615621 (2010).

https://doi.org/10.1007/s11274-009-0211-3

[44] Magaña S. M., Quintana P., Aguilar D. H., Toledo J. A., Ángeles-Chávez C., Cortés M. A., León L., Freile-Pelegrín Y., López T., Sánchez R. M. T.: Antibacterial activity of montmorillonites modified with silver. Journal of Molecular Catalysis A: Chemical, 281, 192-199 (2008).

https://doi.org/10.1016/j.molcata.2007.10.024

[45] Rzayev Z. M. O., Erdönmez D., Erkan K., Şimşek M., Bunyatova U.: Functional copolymer/organo-MMT nanoarchitectures. XXII. fabrication and characterization of antifungal and antibacterial poly (vinyl alcoholco-vinyl acetate/ODA-MMT/AgNPs nanofibers and nanocoatings by e-spinning and c-spinning methods. International Journal of Polymeric Materials and Polymeric Biomaterials, 64, 267-278 (2014).

https://doi.org/10.1080/00914037.2014.936599

[36] Ohashi F., Oya A., Duclaux L., Beguin F.: Structural model calculation of antimicrobial and antifungal agents derived from clay minerals. Applied Clay Science, 12, 435-445 (1998). https://doi.org/10.1016/S0169-1317(98)00008-8

[47] Zhao D., Zhou J., Liu N.: Preparation and characterization of Mingguang palygorskite supported with silver and copper for antibacterial behavior. Applied Clay Science, 33, 161-170 (2006). https://doi.org/10.1016/j.clay.2006.04.003

[48] Dinçer S., Köseli V., Kesim H., Rzaev Z. M. O., Pişkin E.: Radical copolymerization of $N$-isopropylacrylamide with anhydrides of maleic and citraconic acids. European Polymer Journal, 38, 2143-2152 (2002). https://doi.org/10.1016/S0014-3057(02)00127-1

[49] Peker N., Rzaev Z, M. O., Güven O.: Synthesis and characterization of poly $(\mathrm{N}$ vinylimidazole-co-acrylonitrile) and determination of monomer reactivity ratios. Macromolecular Chemistry and Physics, 205, 1088-1095 (2004).

https://doi.org/10.1002/macp.200300130 